\title{
The Elusive Three-Coordinate Dicationic Hydrido Boron Complex
}

Wen-Ching Chen, ${ }^{\dagger}$ Ching-Yu Lee, ${ }^{\dagger, \S}$ Bo-Chao Lin, ${ }^{\dagger}$ Yu-Chen Hsu, ${ }^{\dagger}$ Jiun-Shian Shen, ${ }^{\dagger}$ Chao-Ping Hsu, ${ }^{*}{ }^{\dagger}$ Glenn P. A. Yap, and Tiow-Gan Ong*, ${ }^{\ddagger}, \|$

${ }^{\dagger}$ Institute of Chemistry, Academia Sinica, Nangang, Taipei, Taiwan, Republic of China

${ }^{\S}$ Department of Chemical Engineering, National Taiwan University of Science and Technology, Taipei, Taiwan, Republic of China

"The Department of Applied Chemistry, National Chiao Tung University, Hsinchu, Taiwan, Republic of China

${ }^{\ddagger}$ Department of Chemistry and Biochemistry, University of Delaware, Newark, Delaware 19716, United States

Supporting Information

ABSTRACT: The formation of a hitherto unknown three-coordinate dicationic hydrido boron complex is described. Interestingly, supporting ligand carbodicarbene gave unprecedented reaction with $\mathrm{BH}_{3}$ without using more highly electrophilic Lewis acid precursors. Spectroscopic, crystallographic, and computational analysis was performed to understand the electronic features of these species.

$\mathrm{T}$ he search for unique bonding environments of boron species featuring elusive electronic configurations has been a central theme in molecular main group chemistry. ${ }^{1}$ To date, three classes of monocationic boron(III) adducts have been isolated and identified as boronium $\left[\mathrm{R}_{2} \mathrm{BL}_{2}\right]^{+}$, borenium $\left[\mathrm{R}_{2} \mathrm{BL}\right]^{+}$, and borinium $\left[\mathrm{R}_{2} \mathrm{~B}\right]^{+}$ions. $^{2}$ Such fundamental investigations on cationic boron species have led to an accumulation of knowledge for a broad range of potential applications including polymerization, ${ }^{3}$ hydroboration of alkenes, ${ }^{4}$ and dehydrogenation of ammonia-borane. ${ }^{5}$ In stark contrast to monocationic boron, persistent dicationic boron is less common and poorly defined. The groups of Cowley (I), Himmel (II), and Braunschweig (III) have contributed pioneering work for boron dication chemistry (Scheme 1, top row). ${ }^{6 a-d}$ However, since then relatively few dicationic hydrido boron complexes (IV-VI) have been reported. ${ }^{6 e-g}$ The majority of

\section{Scheme 1. Various Boron Dications I-VI}

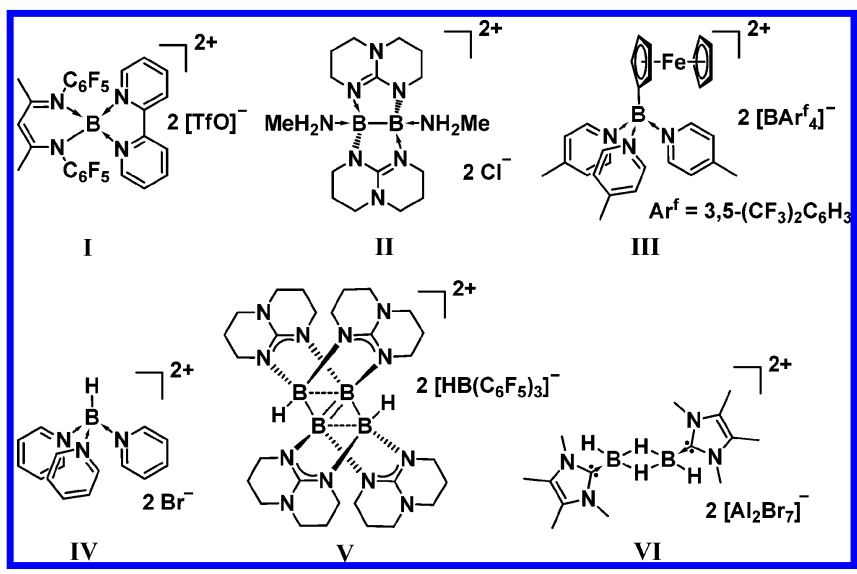

these dicationic derivatives are isolated and characterized as either four-coordinate or bridging adducts at boron.

Stable singlet carbenes featuring strong electron-pair donation such as N-heterocyclic carbenes (NHCs) ${ }^{7}$ and cyclic(alkyl)(amino) carbenes (CAACs) ${ }^{8}$ have been successfully utilized to stabilize highly reactive boron species like boryl radicals, ${ }^{9}$ borenium cations, ${ }^{10}$ boryl anions, ${ }^{11}$ borylenes, ${ }^{12}$ diborene, ${ }^{13}$ and diboryne. ${ }^{14}$ Yet, to date a dicationic species of threecoordinate hydrido boron, $\left[\mathrm{L}_{2} \mathrm{~B}-\mathrm{H}\right]^{2+}$ still remains elusive. Recent work by Alcarazo utilized a more unconventional strong $\sigma$-donating ligand framework (carbodiphosphoranes) containing two electron lone pairs to support highly reactive dihydridoborenium cation species. ${ }^{10 \mathrm{~b}}$ Similarly, another subgroup of potential ligand candidates, so-called carbodicarbenes, ${ }^{15}$ or bent allenes are rarely exploited in supporting main group elements. ${ }^{16}$ Owing to its two dative electron pairs residing on the carbon atom and unique structural morphology, and with the hopes of challenging conceptual limitations and uncovering novel reactivity, we sought to extend the utilities of this ligand scaffold to the realm of boron compounds. Herein, we report a serendipitous discovery of the parent three-coordinate dicationic boron hydride via carbodicarbene routes. The synthesis, isolation, characterization, and computational analysis of these species are discussed.

Previously, we have successfully prepared carbodicarbene $\mathbf{1}$ with sterically encumbered isopropyl side arms as illustrated in Scheme $2 .{ }^{17}$ With the carbodicarbene in hand, we attempted to investigate the coordination chemistry of 1 toward group 13 elements. Addition of carbodicarbene 1 to a slightly excess of $\mathrm{BH}_{3}$-THF (2 equiv) in THF solution afforded compound 3a as a yellow solid in moderate yield (Scheme 2 ). In marked contrast to most borane-NHC complexes, ${ }^{18} 3 \mathrm{a}$ is found to be sparingly soluble in most organic solvents with the exception of dichloromethane, indicating a possible formation of ionic species but negating the existence of product borane 2 . The ${ }^{1} \mathrm{H}$ NMR spectrum of $3 \mathbf{a}$ is notably different from its starting material $\mathbf{1}$ with two distinct septet environments at 5.48 and $4.25 \mathrm{ppm}$ assigned as isopropyl methine protons. In addition, two highfield peaks at $0.06 /-0.55 \mathrm{ppm}$ of equal intensity which integrate for 8 protons and display characteristic coupling of ${ }^{11} \mathrm{~B}$ and ${ }^{10} \mathrm{~B}$ are assigned as $\mathrm{BH}_{4}^{-}$anion.

Received: December 4, 2013

Published: January 2, 2014 
Scheme 2. Synthesis of B and Al Complexes 3 and 4

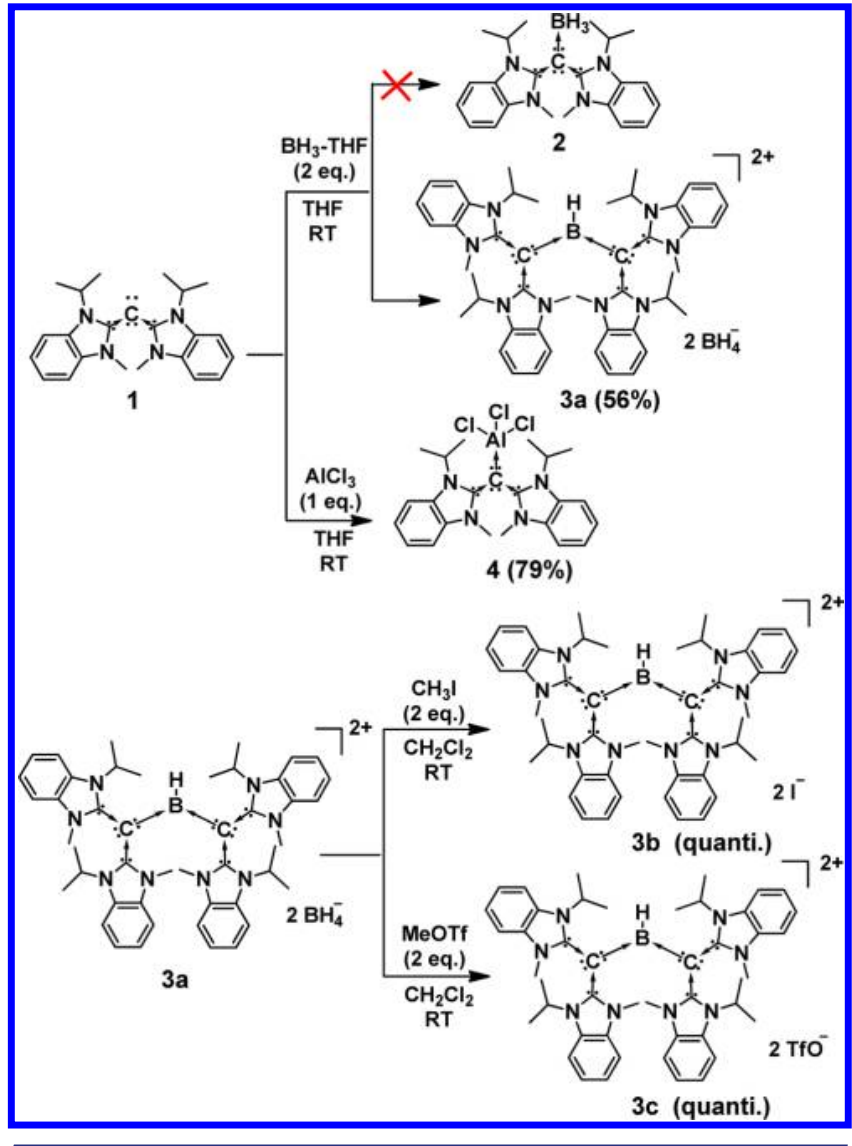

Crystals of 3a suitable for single-crystal X-ray diffraction analysis were obtained by cooling a saturated solution in dichloromethane and ether at $-15{ }^{\circ} \mathrm{C}$ (Figure 1). To our astonishment, the solid-state structure revealed the parent molecule of $3 \mathrm{a}$ to contain a dicationic boron complex and $\mathrm{BH}_{4}$ anions cocrystallized with two dichloromethane molecules; this is markedly different than the coordination environment

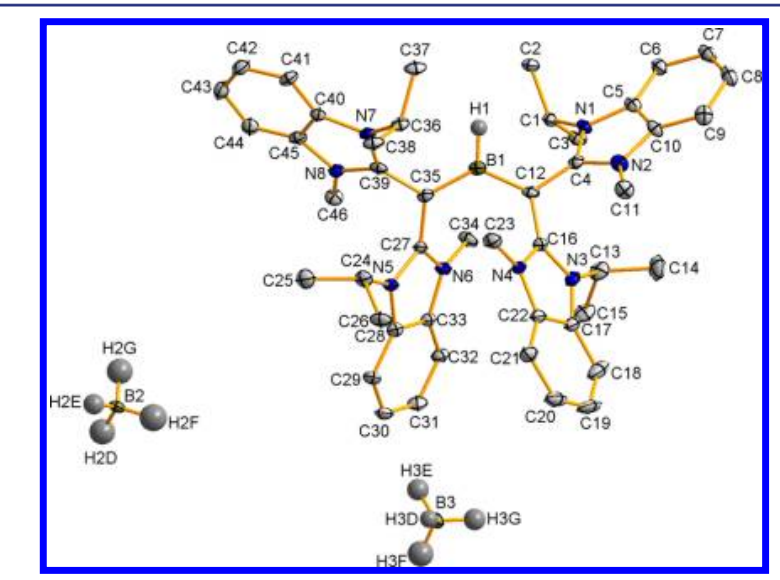

Figure 1. Molecular diagram of 3a with thermal ellipsoids drawn at the $30 \%$ probability level. Solvent molecules and hydrogen atoms, with the exception of the $\mathrm{BH}$, are omitted for clarity. Selected bond lengths $(\AA)$ and angles $\left({ }^{\circ}\right)$ : $\mathrm{C}(12)-\mathrm{B}(1) 1.534(7), \mathrm{C}(35)-\mathrm{B}(1) 1.523(7), \mathrm{C}(12)-$ $\mathrm{C}(4) 1.428(6), \mathrm{C}(12)-\mathrm{C}(16) 1.443(6), \mathrm{C}(4)-\mathrm{N}(1) 1.375(5), \mathrm{C}(4)-$ $\mathrm{N}(2) 1.369(6), \mathrm{C}(16)-\mathrm{N}(3) \quad 1.367(5), \mathrm{C}(16)-\mathrm{N}(4) 1.373(5)$, $\mathrm{C}(12)-\mathrm{B}(1)-\mathrm{C}(35)$ 127.5(3), $\mathrm{C}(4)-\mathrm{C}(12)-\mathrm{B}(1)$ 120.8(3), $\mathrm{C}(4)-$ $\mathrm{C}(12)-\mathrm{C}(16) 114.7(4)$. observed for $\mathrm{NHC}_{-} \mathrm{BH}_{3}$. Compound $3 \mathbf{a}$ features a trigonal planar boron environment with $\mathrm{C} 35-\mathrm{B} 1-\mathrm{C} 12$ bond angle of 127.5(3) ${ }^{\circ}$ coordinated via two carbodicarbenes 1 and a hydride ligand. The carbodicarbene carbons $\mathrm{C} 12$ and C35, boron, and hydrogen $\mathrm{H} 1$ are in a perfectly planar arrangement around the $\mathrm{B}$ atom (sum of angles $=359.8^{\circ}$ ). Boron-carbodicarbene bond distances in 3a are 1.534 (7) and 1.523 (7) $\AA$, which are shorter than $\mathrm{C}-\mathrm{B}$ single bonds known for other borenium cations supported by NHC $(1.58 \AA) .{ }^{10 a}$ The $\mathrm{C}-\mathrm{B}$ bond distances of borenium cation ligated by carbodiphosphoranes $(1.5030 \AA)^{10 \mathrm{~b}}$ and borylene $(\mathrm{H}-\mathrm{B}:)(1.517 \AA)^{12 \mathrm{c}}$ stabilized by cyclic (alkyl)(amino)carbenes are shorter than 3a.

In addition to single crystal X-ray analysis, ${ }^{11} \mathrm{~B}$ NMR and IR spectroscopic analysis was also conducted. The decoupled ${ }^{11} \mathrm{~B}$ NMR of dicationic 3 displayed two signals at $\delta-38.6$ and -25.4 $\mathrm{ppm}$. The former boron resonance is identified as $\mathrm{BH}_{4}^{-}$, while the latter slightly downfield shifted signal is assigned to a cationic borane species. Examination of the solid-state IR spectra of 3a shows four strong IR absorptions bands at 2395.6, 2282.9, 2217.3 , and $2148.3 \mathrm{~cm}^{-1}$ in the spectral region ascribed to $\mathrm{B}-\mathrm{H}$ stretching. However, the $\mathrm{B}-\mathrm{H}$ stretching mode of a cationic $\mathrm{B}-$ $\mathrm{H}$ cannot be discerned clearly from that of $\mathrm{BH}_{4}^{-}$. In order to resolve this ambiguity, replacement of $\mathrm{BH}_{4}^{-}$with other anionic components was attempted. To our delight, dicationic boron $\mathbf{3 b}$ bearing iodide anions could be obtained through the reaction of 3a with methyl iodide in quantitate yield, which is verified by single crystal X-ray diffraction (see Figure S2). The structural features of $\mathbf{3 b}$ are no different from $\mathbf{3 a}$, thus it warrants no further discussion. The IR of $\mathbf{3 b}$ was performed, and a weak absorption at $2452 \mathrm{~cm}^{-1}$ assigned to the $\mathrm{B}-\mathrm{H}$ stretching mode confirmed the presence of the hydrogen atom at boron. To the best of our knowledge, compound 3 represents the first isolated threecoordinate dicationic hydrido boron species. More intriguingly, the formation of 3 based on the carbodicarbene scaffold gave unprecedented reaction with $\mathrm{BH}_{3}$ without using a more highly electrophilic Lewis acid. This reaction behavior has not been observed for other common NHC ligands supporting borane, where typical reactivity would lead to the formation of a bridging hydride species in order to compensate for the inherent electron deficiency in the boron atom. ${ }^{6 f, g}$

Motivated by the unique structural features manifested in 3 , we wanted to explore another neutral electropositive group 13 element like $\mathrm{Al}$ for comparative purposes. ${ }^{19}$ Carbodicarbene 1 was allowed to react with $\mathrm{AlCl}_{3}$ in THF at ambient temperature to furnish 4 in high yield (79\%). Crystals of $\mathbf{4}$ suitable for single crystal X-ray diffraction analysis were obtained by slow cooling of saturated solution of 4 in toluene at $-15{ }^{\circ} \mathrm{C}$; the resulting solidstate structure is presented in Figure 2. Complex 4 is the first isolated $\mathrm{Al}$ complex supported by the carbodicarbene ligand framework. The structure consists of a distorted tetrahedral Al center with an Al-carbodicarbene bond length of 1.976(3) A, which is slightly shorter than those typically reported for $\mathrm{Al}$ NHC's. ${ }^{20}$ Careful examination of the structural parameters of 4 , reveals an increase in bond length within the $\mathrm{C}-\mathrm{C}-\mathrm{C}$ allenic moiety $(1.453(3)$ and $1.374(4) \AA$ ) with respect to the free carbodicarbene $1(1.335 \AA) .{ }^{15 a, 17}$ This is attributed to donation of electron density from the carbodicarbene to the electron poor $\mathrm{AlCl}_{3}$ moiety. This would in turn significantly shorten the bond lengths of $\mathrm{N}(3)-\mathrm{C}(13)-\mathrm{N}(4)(1.359(3)$ and 1.344(3) $\AA$ ) in only one of the benzimidazolium groups within the ligand framework (Scheme 3 (left)). Compared to 4, the bond lengthening and electron depletion within allenic moieties of 3a $(\sim 1.43 \AA)$ is even more pronounced than its aluminum 


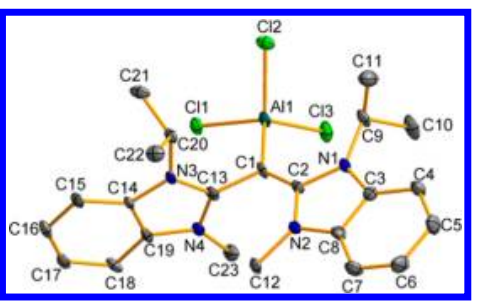

Figure 2. Molecular diagram of $\mathbf{4}$ with thermal ellipsoids drawn at the $30 \%$ probability level. Solvent molecules and hydrogen atoms are omitted for clarity. Selected bond lengths $(\AA)$ and angles $\left({ }^{\circ}\right)$ : $\mathrm{Al}(1)-$ $\mathrm{C}(1)$ 1.976(3), C(1)-C(2) 1.374(4), C(1)-C(13) 1.453(3), N(1)$\mathrm{C}(2)$ 1.403(3), $\mathrm{N}(2)-\mathrm{C}(2)$ 1.393(3), $\mathrm{N}(3)-\mathrm{C}(13) 1.359(3), \mathrm{N}(4)-$ $\mathrm{C}(13) 1.344(3), \mathrm{C}(2)-\mathrm{C}(1)-\mathrm{C}(13) 120.3(2), \mathrm{C}(2)-\mathrm{C}(1)-\mathrm{Al}(1)$ 132.33(19), $\mathrm{C}(13)-\mathrm{C}(1)-\mathrm{Al}(1)$ 107.26(18), N(2)-C(2)-N(1) 104.9(2), N(4)-C(13)-N(3) 107.7(2).

Scheme 3. Summaries of the Bond Distance Parameters for Compound 4 (left) and 3a (right)

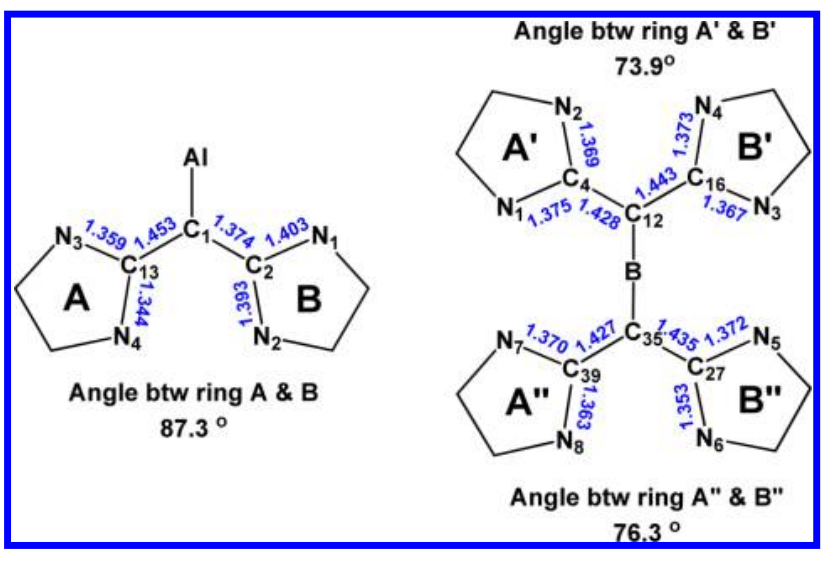

analogues, indicating the highly positive nature of boron species 3a.

In an effort to further understand the electronic nature of 3 and 4, computational calculations at the $\mathrm{B} 3 \mathrm{LYP} / 6-31 \mathrm{G}^{*}$ level were undertaken. Based on natural population analysis (Figure 3, top left $)^{21}$ the boron of compound 3 has a small positive charge $(+0.36)$, since each $\mathrm{C}(12 / 35)$ on benzimidazolyl fragment carries a value of -0.65 . Additionally, natural bond orbital (NBO) analysis ${ }^{22}$ of 3 also indicates the existence of both $\sigma$ - and $\pi$-bonds between $\mathrm{B}$ and the two $\mathrm{C}$ atoms (Figure 3, bottom). Both bonding modes feature significant contribution from the $\mathrm{C}$ atom ( 68 and $83 \%$, respectively), indicating an electron-donating effect from $\mathrm{C}$ to $\mathrm{B}$ involving two electron pairs of carbodicarbene ligand.

Likewise, calculations showed that the stability of the dicationic boron is further enhanced via electronic conjugation within the allenic NHC motif by dispersing away positive charge accumulated on the boron atom, as seen by the positive $0.72-$ 0.78 charges accumulated in each of the four benzimidazolyl groups (Figure 3, top left). On the contrary, for compound 4, the positive charge is more concentrated on the $\mathrm{Al}$ atom, +1.46 (Figure 3, top right). The two benzimidazolyl groups bear +0.70 and +0.41 charges, respectively. The asymmetric $\mathrm{C}-\mathrm{C}$ bond lengths in the allenic moiety are consistent with those in the $\mathrm{X}$ ray structure. The higher resonance conjugation observed in 4 also contributes to the stability of the dication with the highly electron-deficient $\mathrm{B}$ center.

In conclusion, we have described the formation of a hitherto unknown three-coordinate dicationic borane bearing a hydride

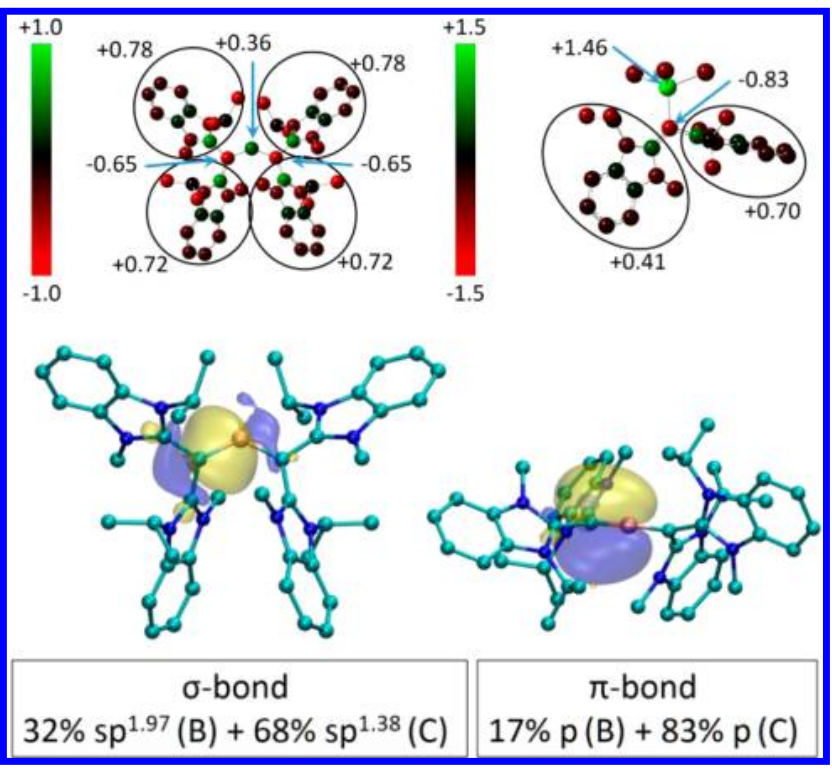

Figure 3. Top panels: natural population analysis for 3 (left) and 4 (right). Shown are values in electronic charges, for the $\mathrm{B}$ (for 3 , or $\mathrm{Al}$ for 4) atom, the nearest $C$ atom, and the sum of charges for benzimidazolyl groups. Bottom panels: NBOs for the $\sigma$-(left) and $\pi$-(right) bond between $\mathrm{B}$ and $\mathrm{C}$ for 3 . $^{23}$

ligand. Interestingly, supporting ligand carbodicarbene gave unprecedented reaction with $\mathrm{BH}_{3}$ without using more highly electrophilic Lewis acid precursors; a reaction behavior not observed for other common NHC ligands. The subtle variation in bonding parameters of carbodicarbene ligands vs NHC's demonstrated that the stability of highly charged main group complexes like 3 could be accessed through charge delocalization with resonance conjugation and additional $\pi$-symmetry donation from second electron pairs. Although this serendipitous finding can currently be regarded as a laboratory curiosity, these results pave the way for future studies in highly electrophilic Lewis acid chemistry with interesting potential applications in organic synthesis and catalysis. Our ongoing efforts focus on extending this strategy to the isolation of other highly electrophilic boron species for the discovery of unprecedented bonding arrangements and novel concomitant reactivity.

\section{ASSOCIATED CONTENT}

\section{Supporting Information}

Experimental details and characterization data. This material is available free of charge via the Internet at http://pubs.acs.org.

\section{AUTHOR INFORMATION}

\section{Corresponding Author}

tgong@gate.sinica.edu.tw

Notes

The authors declare no competing financial interest.

\section{ACKNOWLEDGMENTS}

This work is financially supported by National Science Council of Taiwan (NSC-101-2628-M-001-002-MY3 grant) and Academia Sinica Funding. We also thank Dr. Mei-Chin Tseng for generous technical support for using the Mass Analysis facility. Finally, we are grateful for Professor Ching-Wen Chiu (National Taiwan University, Taipei) and Dr. Titel Jurca (University of Bristol) for their valuable suggestions and discussions. 


\section{REFERENCES}

(1) Davidson, M. G.; Wade, K.; Marder, T. B.; Hughes, A. K. Contemporary Boron Chemistry; Royal Society Chemistry: London, 2000.

(2) (a) Kölle, P.; Nöth, H. Chem. Rev. 1985, 85, 399. (b) Piers, W. E.; Bourke, S. C.; Conroy, K. D. Angew. Chem. Int. Ed. 2005, 44, 5016.

(3) Wie, P.; Atwood, D. A. Inorg. Chem. 1998, 37, 4934.

(4) Prokofjevs, A.; Boussonnière, A.; Li, L.; Bonin, H.; Lacôte, E.; Curran, D. P.; Vedejs, E. I. Am. Chem. Soc. 2012, 134, 12281.

(5) (a) Stephens, F. H.; Baker, R. T.; Matus, M. H.; Grant, D. J.; Dixon, D. A. Angew. Chem. Int. Ed. 2007, 46, 746. (b) Stephens, F. H.; Pons, V.; Baker, R. T. Dalton Trans. 2007, 2613. (c) O'Neill, M.; Addy, D. A.; Riddlestone, I.; Kelly, M.; Phillips, N.; Aldridge, S. J. Am. Chem. Soc. 2011, 133, 11500.

(6) (a) Vidovic, D.; Findlater, M.; Cowley, A. H. J. Am. Chem. Soc. 2007, 129, 8436. (b) Dinda, R.; Ciobanu, O.; Wadepohl, H.; Hübner, O.; Acharyya, R.; Himmel, H.-I. Angew. Chem. Int. Ed. 2007, 46, 9110. (c) Braunschweig, H.; Kaupp, M.; Lambert, C.; Nowak, D.; Radacki, K.; Schinzel, S.; Uttinger, K. Inorg. Chem. 2008, 47, 7456. (d) Vidovic, D.; Findlater, M.; Cowley, A. H. I. Am. Chem. Soc. 2007, 129, 11296. (e) Vargas-Baca, I.; Findlater, M.; Powell, A.; Vasudevan, K. V.; Cowley, A. H. Dalton Trans. 2008, 6421. (f) Litters, S.; Kaifer, E.; Enders, M.; Himmel, H.-J. Nat. Chem. 2013, 5, 1029. (g) Prokofjevs, A.; Kampf, J. W.; Solovyev, A.; Curran, D. P.; Vedejs, E. I. Am. Chem. Soc. 2013, 135, 15686.

(7) Dröge, T.; Glorius, F. Anoew. Chem. Int. Ed. 2010, 49, 6940.

(8) Melaimi, M.; Soleilhavoup, M.; Bertrand, G. Angew. Chem., Int. Ed. 2010, 49, 8810.

(9) (a) Ueng, S.-H.; Brahmi, M. M.; Derat, É.; Fensterbank, L.; Lacôte, E.; Malacria, M.; Curran, D. P. I. Am. Chem. Soc. 2008, 130, 10082. (b) Ueng, S.-H.; Solovyev, A.; Yuan, X.; Geib, S. J.; Fensterbank, L.; Lacôte, E.; Malacria, M.; Newcomb, M.; Walton, J. C.; Curran, D. P. J. Am. Chem. Soc. 2009, 131, 11256. (c) Walton, J. C.; Brahmi, M. M.; Fensterbank, L.; Lacôte, E.; Malacria, M.; Chu, Q.; Ueng, S.-H.; Solovyev, A.; Curran, D. P. I. Am. Chem. Soc. 2010, 132, 2350. (d) Monot, J.; Solovyev, A.; Bonin-Dubarle, H.; Derat, É.; Curran, D. P.; Robert, M.; Fensterbank, L.; Malacria, M.; Lacôte, E. Angew. Chem., Int. Ed. 2010, 49, 9166. (e) Solovyev, A.; Chu, Q.; Geib, S. J.; Fensterbank, L.; Malacria, M.; Lacôte, E.; Curran, D. P. J. Am. Chem. Soc. 2010, 132, 15072. (f) Walton, J. C.; Brahmi, M. M.; Monot, J.; Fensterbank, L.; Malacria, M.; Curran, D. P.; Lacôte, E. J. Am. Chem. Soc. 2011, 133, 10312.

(10) (a) Matsumoto, T.; Gabbaï, F. P. Organometallics 2009, 28, 4252. (b) Inés, B.; Patil, M.; Carreras, J.; Goddard, R.; Thiel, W.; Alcarazo, M. Angew. Chem. Int. Ed. 2011, 50, 8400. Other types of borenium cations have been described: (c) Chiu, C.-W.; Gabbaï, F. P. Organometallics 2008, 27, 1657. (d) Bonnier, C.; Piers, W. E.; Parvez, M.; Sorensen, T. S. Chem. Commun. 2008, 4593. (e) Someya, C. I.; Inoue, S.; Präsang, C.; Irran, E.; Driess, M. Chem. Commun 2011, 47, 6599. (f) Tsurumaki, E.; Hayashi, S.; Tham, F. S.; Reed, C. A.; Osuka, A. J. Am. Chem. Soc. 2011, 133, 11956. (g) De Vries, T. S.; Prokofjevs, A.; Vedejs, E. Chem. Rev. 2012, 112, 4246. (h) Chen, J.; Lalancette, R. A.; Jäkle, F. Chem. Commun. 2013, 49, 4893.

(11) (a) Braunschweig, H.; Chiu, C.-W.; Radacki, K.; Kupfer, T. Angew. Chem. Int. Ed. 2010, 49, 2041. (b) Monot, J.; Solovyev, A.; BoninDubarle, H.; Derat, É.; Curran, D. P.; Robert, M.; Fensterbank, L.; Malacria, M.; Lacôte, E. Angew. Chem., Int. Ed. 2010, 49, 9166. (c) Ruiz, D. A.; Ung, G.; Melaimi, M.; Bertrand, G. Angew. Chem., Int. Ed. 2013, 52, 7590. Other types of boryl anions have been described: (d) Marder, T. B. Science 2006, 314, 69. (e) Segawa, Y.; Yamashita, M.; Nozaki, K. Science 2006, 314, 113. (f) Braunschweig, H.; Burzler, M.; Dewhurst, R. D.; Radacki, K. Angew. Chem. Int. Ed. 2008, 47, 5650.

(12) (a) Bissinger, P.; Braunschweig, H.; Kraft, K.; Kupfer, T. Angew. Chem., Int. Ed. 201 1, 50, 4704. (b) Wang, Y.; Robinson, G. H. Science 2011, 333, 530. (c) Kinjo, R.; Donnadieu, B.; Celik, M. A.; Frenking, G.; Bertrand, G. Science 2011, 333, 610. (d) Curran, D. P.; Boussonnière, A.; Geib, S. J.; Lacôte, E. Anoew. Chem.. Int. Ed. 2012, 51, 1602. (e) Celik, M. A.; Sure, R.; Klein, S.; Kinjo, R.; Bertrand, G.; Frenking, G. Chem.-Eur. J. 2012, 18, 5676.
(13) Wang, Y.; Quillian, B.; Wei, P.; Wannere, C. S.; Xie, Y.; King, R. B.; Schaefer, H. F.; Schleyer, P. v. R.; Robinson, G. H. J. Am. Chem. Soc. 2007, 129, 12412.

(14) Braunschweig, H.; Dewhurst, R. D.; Hammond, K.; Mies, J.; Radacki, K.; Vargas, A. Science 2012, 336, 1420.

(15) (a) Dyker, C. A.; Lavallo, V.; Donnadieu, B.; Bertrand, G. Angew. Chem. Int. Ed. 2008, 47, 3206. (b) Fürstner, A.; Alcarazo, M.; Goddard, R.; Lehmann, C. W. Angew. Chem., Int. Ed. 2008, 47, 3210. (c) Viehe, H. G.; Janousek, Z.; Gompper, R.; Lach, D. Angew. Chem., Int. Ed. 1973, 12, 566. (d) Ruiz, D. A.; Melaimi, M.; Bertrand, G. Chem.-Asian I. 2013, 8, 2940.

(16) Inés, B.; Palomas, D.; Holle, S.; Steinberg, S.; Nicasio, J. A.; Alcarazo, M. Angew. Chem.. Int. Ed. 2012, 51, 12367.

(17) Chen, W.-C.; Hsu, Y.-C.; Lee, C.-Y.; Yap, G. P. A.; Ong, T.-G. Organometallics 2013, 32, 2435.

(18) (a) Tang, C. Y.; Smith, W.; Thompson, A. L.; Vidovic, D.; Aldridge, S. Angew. Chem. Int. Ed. 2011, 50, 1359. (b) Curran, D. P.; Solovyev, A.; Brahmi, M. M.; Fensterbank, L.; Malacria, M.; Lacôte, E. Anoew. Chem. Int. Ed. 2011, 50, 10294.

(19) Obviously, $\mathrm{BCl}_{3}$ may appear as an ideal candidate for this purpose. Unfortunately, we experienced synthetic difficulty to obtain any useful adduct due to intractable mixtures in reaction mixture.

(20) (a) Arduengo, A. J.; Dias, H. V. R.; Calabrese, J. C.; Davidson, F. J. Am. Chem. Soc. 1992, 114, 9724. (b) Shih, W.-C.; Wang, C.-H.; Chang, Y.-T.; Yap, G. P. A.; Ong, T.-G. Organometallics 2009, 28, 1060. (c) Tai, C.-C.; Chang, Y.-T.; Tsai, J.-H.; Jurca, T.; Yap, G. P. A.; Ong, T.-G. Organometallics 2012, 31, 637.

(21) (a) Reed, A. E.; Weinhold, F. I. Chem. Phys. 1983, 78, 4066. (b) Reed, A. E.; Weinstock, R. B.; Weinhold, F. J. Chem. Phys. 1985, 83, 735 .

(22) Foster, J. P.; Weinhold, F. I. Am. Chem. Soc. 1980, 102, 7211.

(23) Bottom panel of Figure 3 was produced with VMD software. Humphrey, W.; Dalke, A.; Schulten, K. I. Mol. Graphics 1996, 14, 33. 